\title{
Vocabulary and Identification of Information: Difficulties and Challenges in Word Problems Solving
}

\author{
John Carlo P. Unson ${ }^{1}$ \\ ${ }^{1}$ University of the Cordilleras, Baguio City, Philippines
}

\begin{abstract}
Word problems solving continues to be a problem for both students and teachers alike. As researches in word problem solving along reading comprehension are continuously undertaken, the problem remains timely and relevant as only few have shed light into the difficulties and challenges in word problem solving brought about by vocabulary and identification of information. This research intends to identify the areas of difficulties and challenges experienced by students and teachers in the senior high department in a top university in the Philippines, the University of the Cordilleras, which has a wide array of quality programs in the said department. Results obtained in this research may be used not only by students and teachers but also by authors, parents, aspiring teachers, aspiring school owners, or anyone who aspires for their personal development in Mathematics.
\end{abstract}

Keywords: word problems solving, Mathematics, senior high Philippines.

\section{Introduction}

\subsection{Mathematics}

Mathematics has been proven to be a vital, indispensable tool in life. It is a part of life. As a matter of fact, every citizen should acquire competence and development of power in quantitative competence and in the use of Mathematics procedure in daily living (Laurito et al., 2016). According to Ogena (2010), it is one of the subjects in education that is recognized as a major factor in development which consequently becomes an area for national agenda to focus on. Furthermore, the United States (National Research Council, 2001; as cited by Suan, 2014) and other countries (Ketterlin - Geller et al, 2008), have taken the development of mathematical reasoning as their goal for these skills are of importance in employment. Hence, it is poignant for the Philippines to also be able to adapt this development alongside the nation's development. Mathematics is essential to one's development on a micro scale and expands to a nation's development on a macro level. These cement the fact that Mathematics is neither an option nor a choice but a reality to be accepted and embraced as it is incorporated in life.

\subsection{Word Problems Solving}

A more specific concept in Mathematics is problem solving or word problems solving which displays importance in various contexts of everyday life (dela Cruz and Lapinid, 2014; Raduan, 2010). These problems spice lives be it in the simplicity of budgeting allowances, measuring time needed to complete a task, partitioning the amount of ingredients needed for a meal, until the complexity of measurements of supplies in carpentry and distances needed to complete a travel. Problem solving is an effort to overcome obstacles in order to reach a goal using some cognitive and metacognitive skills (Wrekelgram, 1974; as cited by Raduan, 2010). The best way to get to solving these problems is to face them. One gets the sense of fulfilment and confidence when he is able to solve problems successfully.

Academically, word problem solving entails students to be able to interpret problems correctly before they proceed to the computation of the answers (Langenes, 2011). These pose challenges to students as these require them to read and comprehend the problem, identify what needs to be answered, and come up with the corresponding equations that will be solved (Krick - Morales, 2006; as cited by Cruz and Bullecer, 2016). In consonance, word problems are intricate language constructions which contain unfamiliar words, 
complex combinations of text and numbers, and considerable amounts of information to decode and organize. Young readers who are confused and distracted by everyday language, math words, or combinations of both may know how to do the necessary math operations, yet answer incorrectly because they do not clearly comprehend what the question is asking them to do. Others may be confused about the math operations needed for the problem. Those who struggle with both reading and math face the biggest challenges. These youngsters are the least successful with word problems, performing worse than students with only Mathematics difficulties or students experiencing neither Reading nor Mathematics difficulties (Fuchs and Fuchs, 2002; as cited by Edwards, Maloy, and Anderson, 2009).

Students, especially in grade school, have difficulties in the analyses and interpretation of word problems as opposed to being given problems already expressed in mathematical sentence (dela Cruz and Lapinid, 2014). This is not only limited to those who are in grade school. If left unaddressed, these difficulties will continue to persist until senior high school, higher education, and even in the realm of profession. Hence, these pose problems in senior high school as it is the stage where one is prepared to be competent for both higher studies and profession. It is expected for one to be able to solve problems that are encountered in order to be competent. Hence, the statement solidifies that Mathematics, specifically problem-solving skills, equip, prepare, and shape one to be prepared for the future. All the more should problem solving be an area of focus in education. Nonetheless, word problems have been a relatively understudied component of math and literacy training (Powell, Fuchs, Fuchs, Cirino, and Fletcher, 2009; as cited by Edwards, Maloy, and Anderson, 2009). Literacy coaches and teachers need wide-ranging strategies in order to support children as they improve their skills in reading and Mathematics. By using novelty, flexibility, and creativity of response, together, they can help students deepen and broaden an understanding of the languages of words and numbers found in math word problems (Edwards, Maloy, and Anderson, 2009).

\subsection{Reading Comprehension in Word Problems Solving}

Vilenius-Tuohimaa, Aunola, and Nurmi (2008) say that reading is related to word problem solving. This is supported by Akbasli, Sahin, and Yaykiran (2016) who saw that countries that were successful in Mathematics and Science were also successful in Reading and vice versa. Hence, reading plays a significant role in solving word problems (Pearce et al., 2013). In addition, students tend to read incorrectly and rush into solving the problem without reading carefully (Özsoy, Kuruyer, and Çakiroglu, 2015; Salemeh and Etchells, 2016). This is supported by Georges (1929), as cited by Eby (2016), who found that lack of intensity and precision in reading led to students' difficulties in solving word problems. Phonapichat, Wongwanich, and Sujiva (2014) and Vula and Kurshumlia (2015) also found that students do not like to read math problems - especially if they are lengthy. This is in coherence to the findings that students see Mathematics as more of numbers and less of words (Vula and Kurshumlia, 2015). Students ignore words, phrases, or sentences in the given problems (Jupri and Drijvers, 2016). Others look for keywords when they go over the problems instead of understanding it. Consequently, incorrect translations are obtained which further result to erroneous solutions (dela Cruz and Lapinid, 2014).

It follows that if one's reading skills is not sharpened, they fail to grasp the problem and the rest of the procedures follow. All the more, if one refuses to have a positive attitude towards reading, they also fail to grasp the problem fully and may not be able to perform the necessary procedures correctly. Thus, reading must be an area of focus when it comes to word problem solving (Angateeah, 2017).

\subsection{Difficulties and Challenges in Word Problem Solving Along Vocabulary and Identification of Information}

Edwards, Maloy, and Anderson (2009) cite the following challenges in solving word problems: unfamiliar vocabulary, proper names, sentence structure and syntax, math terminology, multiple math operations, words and numbers, and visual displays of information.

It was found that difficulties arose due to inability to develop a correct structure of the problem (Angateeah, 2017). This is backed by Seifi, Haghverdi, and Azizmohamadi (2012) and Jupri and Drijvers (2016) who saw that students struggled in word problem representation while Yeo (2009) proved that there are students who had inability to translate problems into mathematical forms. These are supported by Salemeh and 
Etchells (2016) who mention that some students have difficulties in analyzing word problems as they are unable to translate or translate incorrectly. Tambychik and Meerah (2010) cited some of their respondents with one saying that "...solving maths problem is difficult... we have to state the problem into mathematical sentences..." and another that "...one of the difficult tasks in Mathematics is transforming the information concerned into a meaningful mathematical sentence in order to answer the problem." Consequently, students were more at ease when given mathematical sentences rather than word problems (Hite, 2009).

Some students also tend to use the wrong operation (Salemeh and Etchells, 2016). This is backed by Raduan (2010) saying that students do not know which operations are to be put to use in problem solving. Moreover, Yeo (2009), Raduan (2010), and Nguyen and Ngo (2015) found that students lacked knowledge on strategy and the use of correct formulas. For Hite (2009), students still struggle to explain the steps in solving word problems. These are also seen by Raudan (2010) and Njagi (2015) who saw that students had difficulty on which formulas to use. Trance (2013) and Vula and Kurshumlia (2015), on the other hand, saw that students struggled with their processing skills. In addition, Tambychik and Meerah (2010) cite students saying, "How to answer the question? ...in fact, we got so confused on how to solve the problem." Consequently, when students do not know how to answer the problem, they guess without doing any thinking (Phonapichat, Wongwanich, and Sujiva, 2014).

As proper names and combinations of words and numbers are acknowledged to be mere distractors, the other challenges are rooted from difficulties related to vocabulary and identification of information. Reading alongside one's attitude towards it, translation and representation, and knowledge on operations, formulas, and procedure may have also been rooted from the difficulties related to vocabulary and identification of information. One may refuse to read simply because of difficulties in grasping necessary information and in understanding words in a given problem. Consequently, one may not get to perform the necessary steps and fail to use the needed operations in solving because of difficulties in the identification of information and fail to translate problems to mathematical sentences because of difficulties encountered in the comprehension of words. All the more when word problems involve multiple mathematical operations, one may not understand that more than one step is involved in the process (Edwards, Maloy, \& Anderson, 2009). Again, it boils down to the discernment of words and pieces of information that may enable or prevent one to obtain the desired mathematical sentences.

Cimiyotti (2013) saw that vocabulary tests are highly correlated to academic performances in Mathematics. Several researchers also acknowledge vocabulary as a challenge in understanding word problems with some stating that students have struggled with terms used in problems and some adding that students were not familiar with the words used (Tambychik and Meerah, 2010; Seifi, Haghverdi, and Azizmohamadi, 2012; Imam, Abas-Matsura, and Jamil, 2013; Pearce, et al, 2013; Conley, 2014; dela Cruz and Lapinid, 2014; Phonapichat, Wongwanich, and Sujiva, 2014; Njagi, 2015; Vula and Kurshumlia, 2015; Eby, 2016; Salemeh and Etchells, 2016). Jupri and Drijvers (2016) mention that misunderstood words, phrases, and sentences are hindrances in understanding word problems. On a more specific scale, Vula and Kurshumlia (2015) saw that wrong interpretations of the meanings of product and quotient prevented the students from solving correctly. Salemeh and Etchells (2016) add on by citing that "sometimes students do not understand particular words in the problem which frustrates them and leads them to assume that the problem is difficult to solve." Although Edwards, Maloy, and Anderson (2009) suggest that one may ignore unfamiliar or confusing vocabulary and still be able to perform the correct steps and still arrive at the correct answer, teaching students about math terminology has still been shown to improve student performance on math tests (Gifford and Gore, 2008; as cited by Edwards, Maloy, and Anderson, 2009). Thus, teachers can therefore consider to purposefully teach math vocabulary (Edwards, Maloy, and Anderson, 2009).

Salemeh and Etchells (2016) found that some students are distracted by the presence of unnecessary information in the problem. Moreover, Imam, Abas-Mastura, and Jamil (2013) saw that students struggled in the identification of main ideas and the noting of details. For Özsoy, Kuruyer, and Çakiroglu (2015), students misinterpreted problems and failed to determine the required and the given. Furthermore, students had difficulty in making inferences, predicting outcomes, and drawing conclusions (Imam, Abas-Mastura, and Jamil, 2013; Özsoy, Kuruyer, and Çakiroglu, 2015). Similarly, Phonapichat, Wongwanich, and Sujiva 
(2014) saw that students are unable to figure out what to assume and what information from the problem is necessary to solving it. Coherently, Raduan (2010) found that students had a hard time in the identification of information embedded in word problems, the explanation of the said information, and the relation of that information with the needed information. These are also seen by Tambychik and Meerah (2010) who state that students fail to make connections and manipulate information. They elaborate further by citing students' perspectives, saying "I got confused with the questions, teacher... What do the questions want? ...I have problem to understand the language in the question... understanding the problem takes time... we always make mistakes in managing the facts in the questions... we do not know which fact to use first... we are not sure how to make connection... What to look for?" Moreover, Angateeah (2017) saw that some low achievers showed difficulty in paraphrasing the problems while Nguyen and Ngo (2015) saw that students found it hard to summarize a problem. Even successful word problem solvers had a hard time on semantically complex word problems than on less semantically complex (Boonen et al., 2016). Deducing it further, as difficulties in summarizing and paraphrasing are evident, it is indirectly deductible that these yield to traces of difficulties in the identification of information. Going further, Edwards, Maloy, and Anderson (2009) share the same sentiments through the acknowledgement of how problems are written in compositional and not conversational English, thus, making it hard for young readers to recognize information. Additionally, some word problems provide visual displays of information which may be confusing for students and even for adults. These visual displays are also not in sentences or paragraphs which pave way for even more confusion (Edwards, Maloy, and Anderson, 2009). It follows that if one struggles to identify information, it results to struggle in the translation of word problems and failure in attainment of correct representation.

\subsection{Significance and Purpose of the Study}

Generally, reading comprehension is undoubtedly a pre-requisite to solving word problems which means that it would be just right to delve deeper into the matter that is concerned with the said area. Despite a number of researches on difficulties in word problems brought about by difficulties in reading comprehension, the problem still continues to be evident. Moreover, since previous researches have shed light into how reading affects word problems as it is most evident in the translation, it would also be right to scrutinize these difficulties that are brought about in between. Hence, it is even more essential to particularly shed light to difficulties brought about by reading comprehension with respect to the vocabulary and identification of information. Consequently, this research is intended for the investigation of difficulties in word problems in the light of vocabulary and identification of information experienced by $11^{\text {th }}$ grade Science, Technology, Engineering, and Mathematics, or STEM students and senior high school Mathematics teachers.

This research will benefit both students and teachers who would wish to improve their skills in solving and teaching word problems respectively. Moreover, parents, aspiring Mathematics teachers, school owners, Mathematics textbooks authors, and those who simply struggle with and want to be more enlightened with Mathematics will also benefit from this research. Both students and teachers will be enlightened with how strengthening their skills in both the vocabulary and identification of information can help them become better solvers of word problems. Moreover, teachers will be able to discover ways on how they could teach problem solving efficiently and effectively in line with the said skills.

This will aid parents of students struggling in problem solving in addressing their children's struggles in solving word problems. Moreover, the said benefactors too will be able to learn to address their own struggles in problem solving. Aspiring Mathematics teachers will benefit from this research as they incorporate the importance of these skills in their future teaching venture. School owners, and those who wish to put up their own school, may consider embracing ways to make problem solving, or Mathematics in general, more comprehensive. Mathematics textbooks authors will also be able to realize the impact of words in problem solving as well as the importance of identification of information. This research may be able to impact these said benefactors through the consideration of words to be put to use as well as the elaboration of essential words and through the emphasis on information. Lastly, those who struggle with and want to be enlightened with problem solving may also be able to identify the causes of difficulties experienced in the solving process. 
This research aimed to find out the difficulties in problem solving experienced by senior high school students under the academic strand Science, Technology, Engineering, and Mathematics, or STEM, and challenges encountered by senior high school Mathematics teachers, both of the University of the Cordilleras. It sought to answer the following questions: (1) What difficulties in word problems brought about by vocabulary are experienced by $11^{\text {th }}$ grade STEM students along Number Sense, Patterns and Algebra, Geometry and Measurement, and Statistics and Probability? (2) What difficulties in word problems brought about by identification of information are experienced by $11^{\text {th }}$ grade STEM students along Number Sense, Patterns and Algebra, Geometry and Measurement, Statistics and Probability? (3) What challenges are encountered by senior high school math teachers in teaching problem solving along vocabulary and identification of information?

\section{Materials and Methods}

\subsection{Methods}

This research is qualitative in design and used the descriptive method with the aid of questionnaires and interviews. This method was used to identify areas of difficulties and challenges faced by students and teachers in problem solving with respect to vocabulary and identification of information along Number Sense, Patterns and Algebra, Geometry and Measurement, and Statistics and Probability.

The population for this study was $11^{\text {th }}$ grade STEM students and senior high school Mathematics teachers of the University of the Cordilleras. The institution has incorporated all tracks for the senior high school program for three years now, granting prestige to the institution's program. The $11^{\text {th }}$ grade STEM students served as respondents in this study. Using Lynch's formula for sampling, wherein the values 1.96, 0.50, and 0.05 are the normal variable for a reliability level of 0.95 , the largest possible proportion, and the margin of error respectively were used, 305 students was the minimal sample size obtained from a population of 1,476 students. These respondents were selected by means of random, cluster sampling wherein the said number of students comprised 32 sections from where 9 sections were randomly selected even exceeding the sample size with 335 respondents. Furthermore, from these 9 randomly selected sections, 5 sections were randomly selected once more for follow-up interviews. As for the one-on-one interviews, teachers served as key informants in this study and were restricted to a number of 10 teachers. Due to unavailability of teachers and time constraints, only 9 took part.

Prior to the start of the data gathering process, a letter of request was given to the senior high school academic director of the University of the Cordilleras. Once approved, the researcher gave a copy of the letter of request to each teacher of randomly selected class sections in order to be allowed to disseminate questionnaires and to conduct follow-up interviews. As for the one-on-one interviews, the researcher had a hard time in scheduling even at least one key informant as time was running out. This led the researcher to make amends by conducting a group interview instead. Each key informant was given a copy of the letter of request for interview.

Respondents were asked to answer the questionnaire which consisted of the respondents' personal information and 3 problems for each strand giving a total of 12 problems. The respondents were not tasked to solve the said word problems. Instead, they were tasked to encircle words they perceived to have difficulties with and to identify pieces of information for each problem. This questionnaire was validated by the panel after its construction with the aid of the K to 12 Curriculum Guide in Mathematics (2012) and the National Training of Trainers on K to 10: Mathematics 8 (2018). The latter became the main basis in the development of the questionnaire wherein topics for Patterns and Algebra, Geometry and Measurement, and Statistics and Probability were narrowed down and were made more readily available for selection. Since Number Sense is no longer covered from $8^{\text {th }}$ grade onwards, topics from the $7^{\text {th }}$ grade which were obtained through the $\mathrm{K}$ to 12 Curriculum Guide in Mathematics (2012) were the bases in making the problems for this strand. Hence, Mathematics strands that were touched are Number Sense, Patterns and Algebra, Geometry and Measurement, and Statistics and Probability, all of which respondents have already undergone in their junior high school years. A table of specification, which consisted of the number of items per topic, was also constructed. 
Follow-up interviews were scheduled for further discussions on given responses and personal experiences during the time given to answer. These, too, solidified the findings obtained from the questionnaire. A group interview, which was supposedly a series of one-on-one interviews, was administered to key informants with respect to the difficulties encountered by the respondents based on responses from the questionnaire and the follow-up interviews. Conversational guidelines were also used to help keep the said interviews on track.

The data obtained from the questionnaire were classified with respect to themes. As far as vocabulary is concerned, words that respondents have encircled from the questionnaire were classified according to samemeaning words, math-specific words or technical words, and different meaning words (Lee, 2005; as cited by Fatmanissa and Kusnandi, 2017). In terms of identification of information, respondents' answers were classified with respect to the accuracy of responses for each of the three principal parts of a problem identified by Polya (1973) - which are the data, the unknown, and the condition. Responses were classified as follows: Correct, if a response rendered is complete or absolute; responses which are complete yet with additional and unnecessary pieces of information were still considered. Partially Correct, if a response is close to correct but is lacking in information. Incorrect, if a response is problematic in terms of syntax or if a response is deemed incorrect. Lastly, others were sorted Blank where there were no responses. These were all presented in tabular form wherein respective frequencies and percentages were shown to give numerical descriptions for each theme per problem. These results were explained further with their implications, discussions from the interviews, and results from previous, similar researches. Discussions from the group interview were classified via thematic analysis along the observed challenges and practiced remedies.

\section{Results and Discussion}

\subsection{Perceived Difficulties in Vocabulary}

During the collation and transcription of data, challenges were observed from responses as there were students who did not only encircle words and numbers but phrases and sentences as well. Consequently, the researcher only tallied responses which focused on encircling words, numbers, and phrases which pertained to certain concepts or actions but do not have single word equivalents. These were then classified according to the mentioned classification and are presented in tabular form.

\subsubsection{Number Sense}

Table 1 reveals the frequencies and percentages of perceived difficult word types along Number Sense.

Table 1: Difficulties in Problem Solving Brought About by Vocabulary Along Number Sense

\begin{tabular}{|c|c|c|c|c|c|c|}
\hline \multirow[t]{2}{*}{ Item No. } & \multicolumn{2}{|c|}{ Same-meaning words } & \multicolumn{2}{|c|}{ Math-specific words } & \multicolumn{2}{|c|}{$\begin{array}{l}\text { Different-meaning } \\
\text { words }\end{array}$} \\
\hline & $\mathbf{f}$ & $\%$ & $\mathbf{f}$ & $\%$ & f & $\%$ \\
\hline 1 & 33 & 9.90 & 0 & 0.00 & 0 & 0.00 \\
\hline 2 & 24 & 7.20 & 0 & 0.00 & 0 & 0.00 \\
\hline 3 & 14 & 4.20 & 0 & 0.00 & 0 & 0.00 \\
\hline
\end{tabular}

Results for problem number 1 show that out of 335 respondents, only 33 encircled at least one word perceived to be difficult. These $33(9.90 \%)$ indicated difficulties brought about by same-meaning words wherein 28 respondents encircled the word solicit. When asked what the word meant, students were able to grasp the concept as they stated that, "when one solicits, he is asking for money or goods." Other words encircled were: more (2), distribute (2), was (1), to (1), and government (1).

As for problem number 2, only 24 respondents encircled at least one word. Similar to the first problem, all these $24(7.20 \%)$ encircled words which are classified as same-meaning words. Among these 24,11 encircled the word leftover. When respondents found out, they all laughed while looking puzzled as to why the outcome was such. Thus, it was expected that they knew what it meant as they said its Filipino 
translation, "natira”. Other words encircled were: take (4), how much (3), $2 / 5$ (2), took (2), and each (2).

For problem number 3, only 14 respondents encircled at least one word. Likewise, all these 14 (4.20\%) encircled words which are classified as same-meaning words. Among them, 5 encircled the figures 25, 15, and 12 - all of which are pieces of the data. Other words encircled were whether (3), group (2), use (1), both (1), networking (1), and respectively (1).

\subsubsection{Patterns and Algebra}

Table 2 reveals the frequencies and percentages of perceived difficult word types along Patterns and Algebra.

Results for problem number 1 show that out of 335 respondents, only 15 encircled at least one word which they perceived to be difficult. All these $15(4.50 \%)$ encircled same-meaning words wherein 4 encircled the words: 3 times. Other words encircled were: 15 years (3), older (2), 38 years (2), Lilet (2), present ages (2), years (1), than (1), and sum (1).

As for problem number 2, only 11 out of 335 respondents encircled at least one word. Similar to the first problem, all these 11 (3.30\%) encircled same-meaning words where 3 encircled the words: savings account (3). Other words encircled were: beginning (2), withdraw/s (2), transportation (1), present (1), weeks (1), end (1), and at least (1).

Table 2: Difficulties in Problem Solving Brought About by Vocabulary Along Patterns and Algebra

\begin{tabular}{|c|c|c|c|c|c|c|}
\hline \multirow[t]{2}{*}{ Item No. } & \multicolumn{2}{|c|}{ Same-meaning words } & \multicolumn{2}{|c|}{ Math-specific words } & \multicolumn{2}{|c|}{$\begin{array}{l}\text { Different-meaning } \\
\text { words }\end{array}$} \\
\hline & $\mathbf{f}$ & $\%$ & $\mathbf{f}$ & $\%$ & f & $\%$ \\
\hline 1 & 15 & 4.50 & 0 & 0.00 & 0 & 0.00 \\
\hline 2 & 11 & 3.30 & 0 & 0.00 & 0 & 0.00 \\
\hline 3 & 12 & 3.60 & 0 & 0.00 & 0 & 0.00 \\
\hline
\end{tabular}

For problem number 3, only 12 out of 335 respondents encircled at least one word. All these 12 (3.60\%) encircled same-meaning words wherein 6 encircled the word respectively. Other words encircled were: total (3), were (1), special (1), cost (1), and concert tickets (1).

\subsubsection{Geometry and Measurement}

Table 3 reveals the frequencies and percentages of perceived difficult word types along Geometry and Measurement.

Table 3: Difficulties in Problem Solving Brought About by Vocabulary Along Geometry and Measurement

\begin{tabular}{|l|l|l|l|l|l|l|}
\hline Item No. & \multicolumn{3}{|l|}{ Same-meaning words } & \multicolumn{2}{l|}{ Math-specific words } & \multicolumn{2}{l|}{$\begin{array}{l}\text { Different-meaning } \\
\text { words }\end{array}$} \\
\hline & f & $\%$ & f & \% & f & $\%$ \\
\hline 1 & 6 & 1.80 & 24 & 7.20 & 1 & 0.30 \\
\hline 2 & 3 & 0.90 & 8 & 2.40 & 1 & 0.30 \\
\hline 3 & 1 & 0.30 & 28 & 8.40 & 13 & 3.90 \\
\hline
\end{tabular}

Results for problem number 1 show that out of 335 respondents, only 30 encircled at least one word which they perceived to be difficult. Among these respondents, 6 (1.80\%) encircled same-meaning words, 24 
(7.20\%) encircled math-specific words, and $1(0.30 \%)$ encircled a different-meaning word. For the samemeaning words, 3 encircled 3 inches and 3 also encircled the word measurement. As for math-specific words, a majority of 20 respondents encircled the word congruent, 2 for the words third angle, and 2 for the word angle/s. When asked what congruent meant, some students did get that it pertained to two equal sides. As for the third angle, students goofed around saying in Filipino, "yung pangatlong angle". Lastly, the lone encircled word for different-meaning words was the word opposite.

As for problem number 2, only 11 out of 335 respondents encircled at least one word. Among these respondents, $3(0.90 \%)$ encircled same-meaning words, $8(2.40 \%)$ encircled math-specific words, and 1 $(0.30 \%)$ encircled a different-meaning word. For the same-meaning words, the words encircled were: contains (1), line (1) and and (1). As for math-specific words, a majority of 6 respondents encircled the word parallel. When asked what the word parallel meant, students did get that it pertained to lines that do not meet, with some even doing hand gestures of parallel lines. Other words encircled were: $\mathrm{L}_{1}(1)$ and $(3, \mathrm{y})$ (1). Lastly, the lone encircled phrase for different-meaning words were the words, value of y.

For problem number 3, only 36 out of 335 respondents encircled at least one word. Among these respondents, $1(0.30 \%)$ encircled a word under same-meaning words, $28(8.40 \%)$ encircled math-specific words, and 13 (3.90\%) encircled different-meaning words. For the same-meaning words, the word encircled was the word line. As for math-specific words, all 28 encircled the word perpendicular. When asked what the word perpendicular meant, students did get that it pertained to lines that intersected and formed an angle of $90^{\circ}$ with respect to their intersection. Some even did hand gestures of perpendicular lines as they were asked what the word. Finally, for different-meaning words, all 13 encircled the word slope. When asked what the word meant, others did not know how to explain while a few were able to articulate that it pertained to the steepness of a line.

\subsubsection{Statistics and Probability}

Table 4 reveals the frequencies and percentages of perceived difficult word types along Statistics and Probability.

Table 4: Difficulties in Problem Solving Brought About by Vocabulary Along Statistics and Probability

\begin{tabular}{|c|c|c|c|c|c|c|}
\hline \multirow[t]{2}{*}{ Item No. } & \multicolumn{2}{|c|}{ Same-meaning words } & \multicolumn{2}{|c|}{ Math-specific words } & \multicolumn{2}{|c|}{$\begin{array}{l}\text { Different-meaning } \\
\text { words }\end{array}$} \\
\hline & $\mathbf{F}$ & $\%$ & $\mathbf{f}$ & $\%$ & $\mathbf{f}$ & $\%$ \\
\hline 1 & 3 & 0.90 & 0 & 0.00 & 0 & 0.00 \\
\hline 2 & 5 & 1.50 & 0 & 0.00 & 0 & 0.00 \\
\hline 3 & 2 & 0.60 & 5 & 1.50 & 0 & 0.00 \\
\hline
\end{tabular}

Results for problem number 1 show that out of 335 respondents, only 3, encircled at least one word which they perceived to be difficult. All these $3(0.90 \%)$ encircled same-meaning words wherein they encircled: display window (2) and dresses (1).

As for problem number 2, only 5 out of 335 respondents encircled at least one word. Similar to the first problem, all these $5(1.50 \%)$ encircled same-meaning words wherein they encircled: Algebra (3), grades (1), and final grade (1).

For problem number 3, only 7 out of 335 respondents encircled at least one word. Among these respondents, $2(0.60 \%)$ encircled same-meaning words while $5(1.50 \%)$ encircled math-specific words. The word encircled under same-meaning words was the word marbles while the word probability was encircled for math-specific words. 


\subsubsection{Overall}

All word types were perceived to be difficult in at least one strand. Looking into same-meaning words, difficulties in understanding were present all throughout the 4 strands. As for math-specific words, difficulties in understanding were present in the strands of Geometry and Measurement and Statistics and Probability with difficulties in understanding present for all items in the former strand. Lastly, difficulties in understanding different-meaning words were present for all items in Geometry and Measurement.

\subsection{Results in the Identification of Information}

Challenges were also observed from responses when it came to the evaluation of accuracy in the identification of information. Consequently, the researcher evaluated responses with respect to the principal parts. Given figures and their definitions were taken to be strong points for the evaluation of responses for the data. If a respondent gave incorrect figures, regardless of the definitions, the response would be incorrect. However, if the respondent gave correct figures but with hints of incorrect definitions, the response would still be partially correct. Responses for the unknown were more straightforward which led most responses to be either correct or incorrect. However, there were also instances of responses being partially correct when more than one unknown was involved. The condition takes on the procedures or at least the explanation of the concepts needed to be able to solve the problems. Thus, responses which were incorrect at the beginning but were correct in the latter were considered incorrect. Moreover, responses which start out correct but were faulty somewhere in the middle to the end were considered to be partially correct. As for those responses where the concepts were the only given, these too were partially correct for as long as the concept given is correct. All these responses were likewise elaborated on with insights coming from the earlier said interviews.

\subsubsection{Number Sense}

Table 5 reveals the results along Number Sense as it shows the frequencies and percentages of the accuracies of students' responses for each principal part.

Problem number 1 takes on the concept of Operations on Integers wherein results for the identification of the data show that $215(64.20 \%)$ respondents answered partially correct while $4(1.20 \%)$ respondents answered incorrectly. As for the unknown, 300 (89.60\%) respondents answered correctly while $2(0.60 \%)$ answered partially correct. Lastly, for the condition, 133 (39.70\%) got it incorrectly, while 51 (15.20\%) gave partially correct responses.

Table 5: Difficulties in Problem Solving Brought About by Identification of Information Along Number Sense

\begin{tabular}{|c|c|c|c|c|c|c|c|c|c|}
\hline \multirow[t]{2}{*}{ Item No. } & \multirow[t]{2}{*}{$\begin{array}{l}\text { Principal } \\
\text { Parts }\end{array}$} & \multicolumn{2}{|c|}{ Correct } & \multicolumn{2}{|c|}{$\begin{array}{l}\text { Partially } \\
\text { Correct }\end{array}$} & \multicolumn{2}{|c|}{ Incorrect } & \multicolumn{2}{|c|}{ Blank } \\
\hline & & $\mathbf{f}$ & $\%$ & f & $\%$ & f & $\%$ & f & $\%$ \\
\hline \multirow{3}{*}{1} & Data & 103 & 30.7 & 215 & 64.2 & 4 & 1.20 & 13 & 3.90 \\
\hline & Unknown & 300 & 89.6 & 2 & 0.60 & 25 & 7.50 & 8 & 2.40 \\
\hline & Condition & 88 & 26.3 & 51 & 15.2 & 133 & 39.7 & 63 & 18.8 \\
\hline \multirow{3}{*}{2} & Data & 209 & 62.4 & 106 & 31.6 & 7 & 2.10 & 13 & 3.90 \\
\hline & Unknown & 296 & 88.4 & 0 & 0.00 & 25 & 7.50 & 14 & 4.20 \\
\hline & Condition & 194 & $\begin{array}{l}57.9 \\
\end{array}$ & 23 & 6.90 & 63 & 18.8 & 55 & 16.4 \\
\hline \multirow{3}{*}{3} & Data & 204 & 60.9 & 115 & 34.3 & 3 & 0.90 & 13 & 3.90 \\
\hline & Unknown & 274 & 81.8 & 42 & 12.5 & 8 & 2.40 & 11 & 3.30 \\
\hline & Condition & 0 & 0.00 & 63 & 18.8 & 162 & 48.4 & 110 & 32.8 \\
\hline
\end{tabular}

Problem number 2 is a problem on Operations on Rational Numbers wherein results show that with respect to the identification of the data, $209(62.40 \%)$ respondents answered correctly while $7(2.10 \%)$ answered incorrectly. As for the unknown, $274(81.80 \%)$ answered correctly while $0(0.00 \%)$ answered partially correct. Lastly, for the condition, 194 (57.90\%) got the correct answer while $23(6.90 \%)$ got it partially correct. 
Problem number 3 is a problem on Sets wherein in terms of the identification of the data, $204(60.90 \%)$ respondents answered correctly and $3(0.90 \%)$ answered incorrectly. As for the unknown, $296(88.40 \%)$ answered correctly while $8(2.40 \%)$ answered incorrectly. Lastly, for the condition, $162(48.4 \%)$ got it incorrectly while $0(0.00 \%)$ got the correct answer.

\subsubsection{Patterns and Algebra}

Table 6 reveals the results on the survey along Patterns and Algebra as it shows the frequencies and percentages of the accuracies of students' responses for each principal part.

Table 6: Difficulties in Problem Solving Brought About by Identification of Information Along Patterns and Algebra

\begin{tabular}{|c|c|c|c|c|c|c|c|c|c|}
\hline \multirow[t]{2}{*}{ Item No. } & \multirow[t]{2}{*}{$\begin{array}{l}\text { Principal } \\
\text { Parts }\end{array}$} & \multicolumn{2}{|c|}{ Correct } & \multicolumn{2}{|c|}{$\begin{array}{l}\text { Partially } \\
\text { Correct }\end{array}$} & \multicolumn{2}{|c|}{ Incorrect } & \multicolumn{2}{|c|}{ Blank } \\
\hline & & f & $\%$ & $\mathbf{f}$ & $\%$ & $\mathbf{f}$ & $\%$ & $\mathbf{f}$ & $\%$ \\
\hline \multirow{3}{*}{1} & Data & 142 & 42.4 & 150 & 44.8 & 11 & 3.30 & 32 & 9.60 \\
\hline & Unknown & 295 & 88.1 & 8 & 2.40 & 13 & 3.90 & 19 & 5.70 \\
\hline & Condition & 3 & 0.90 & 28 & 8.40 & 147 & 43.9 & 157 & 46.9 \\
\hline \multirow{3}{*}{2} & Data & 68 & 20.3 & 215 & 64.2 & 11 & 3.30 & 41 & 12.2 \\
\hline & Unknown & 288 & 86.0 & 4 & 1.20 & 13 & 3.90 & 30 & 9.00 \\
\hline & Condition & 2 & 0.60 & 118 & 35.2 & 121 & 36.1 & 94 & 28.1 \\
\hline \multirow{3}{*}{3} & Data & 131 & 39.1 & 154 & 46.0 & 3 & 0.90 & 47 & 14.0 \\
\hline & Unknown & 262 & 78.2 & 6 & 1.80 & 34 & 10.1 & 33 & 9.90 \\
\hline & Condition & 0 & 0.00 & 10 & 3.00 & 138 & 41.2 & 187 & 55.8 \\
\hline
\end{tabular}

Problem number 1 takes on Linear Equations particularly that on Age Problems. Results show that for the identification of the data, $150(44.80 \%)$ answered partially correct while $11(3.30 \%)$ answered incorrectly. As for the unknown, $295(88.10 \%)$ answered correctly while $8(2.40 \%)$ answered partially correct. Lastly, for the condition, 157 (46.90\%) left the item blank while only $3(0.90 \%)$ got the correct answer.

Problem number 2 takes on Linear Inequalities wherein $215(64.20 \%)$ gave partially correct responses while $11(3.30 \%)$ gave incorrect responses. As for the unknown, $288(86.00 \%)$ answered correctly while $4(1.20 \%)$ gave partially correct responses. Lastly, for the condition, $121(36.10 \%)$ gave incorrect answers while 2 $(0.60 \%)$ got the correct answer.

Problem number 3 is on Linear Equations but this time dealing with two unknowns. When it comes to the identification of the data, $154(46.00 \%)$ answered partially correct while $3(0.90 \%)$ answered incorrectly. As for the unknown, $262(78.20 \%)$ answered correctly while $6(1.80 \%)$ answered partially correct. Lastly, for the condition, $187(55.80 \%)$ left the item blank while $0(0.00 \%)$ got the correct answer.

\subsubsection{Geometry and Measurement}

Table 7 reveals the results on the questionnaire along Geometry and Measurement as it shows the frequencies and percentages of the accuracies of students' responses for each principal part. 
Table 7: Difficulties in Problem Solving Brought About by Identification of Information Along Geometry and Measurement

\begin{tabular}{|l|l|l|l|l|l|l|l|l|l|}
\hline \multirow{3}{*}{ Item No. } & \multirow{2}{*}{$\begin{array}{l}\text { Principal } \\
\text { Parts }\end{array}$} & \multicolumn{2}{l|}{ Correct } & \multicolumn{2}{l|}{$\begin{array}{l}\text { Partially } \\
\text { Correct }\end{array}$} & \multicolumn{2}{l|}{ Incorrect } & \multicolumn{2}{l|}{ Blank } \\
\cline { 3 - 11 } & & f & $\mathbf{\%}$ & f & \% & f & \% & f & \% \\
\hline \multirow{3}{*}{1} & Data & 100 & $\mathbf{2 9 . 9}$ & 153 & $\mathbf{4 5 . 7}$ & 3 & $\mathbf{0 . 9 0}$ & 79 & $\mathbf{2 3 . 6}$ \\
\cline { 2 - 11 } & Unknown & 234 & $\mathbf{6 9 . 9}$ & 15 & $\mathbf{4 . 5 0}$ & 20 & $\mathbf{6 . 0 0}$ & 66 & $\mathbf{1 9 . 7}$ \\
\cline { 2 - 11 } & Condition & 32 & $\mathbf{9 . 6 0}$ & 7 & $\mathbf{2 . 1 0}$ & 86 & $\mathbf{2 5 . 7}$ & 210 & $\mathbf{6 2 . 7}$ \\
\hline \multirow{3}{*}{2} & Data & 16 & $\mathbf{4 . 8 0}$ & 202 & $\mathbf{6 0 . 3}$ & 3 & $\mathbf{0 . 9 0}$ & 114 & $\mathbf{3 4 . 0}$ \\
\cline { 2 - 11 } & Unknown & 233 & $\mathbf{6 9 . 6}$ & 0 & $\mathbf{0 . 0 0}$ & 6 & $\mathbf{1 . 8 0}$ & 96 & $\mathbf{2 8 . 7}$ \\
\cline { 2 - 11 } & Condition & 2 & $\mathbf{0 . 6 0}$ & 18 & $\mathbf{5 . 4 0}$ & 53 & $\mathbf{1 5 . 8}$ & 262 & $\mathbf{7 8 . 2}$ \\
\hline \multirow{3}{*}{3} & Data & 89 & $\mathbf{2 6 . 6}$ & 116 & $\mathbf{3 4 . 6}$ & 4 & $\mathbf{1 . 2 0}$ & 126 & $\mathbf{3 7 . 6}$ \\
\cline { 2 - 10 } & Unknown & 221 & $\mathbf{6 6 . 0}$ & 3 & $\mathbf{0 . 9 0}$ & 5 & $\mathbf{1 . 5 0}$ & 106 & $\mathbf{3 1 . 6}$ \\
\cline { 2 - 10 } & Condition & 0 & $\mathbf{0 . 0 0}$ & 6 & $\mathbf{1 . 8 0}$ & 70 & $\mathbf{2 0 . 9}$ & 259 & $\mathbf{7 7 . 3}$ \\
\hline
\end{tabular}

Problem number 1 is on Triangle Congruence wherein results show that for the identification of the data, $153(45.70 \%)$ answered partially correct while $3(0.90 \%)$ answered incorrectly. As for the unknown, 234 $(69.90 \%)$ answered correctly while $15(4.50 \%)$ answered partially correct. Lastly, for the condition, 210 $(62.70 \%)$ left it blank while 7 (2.10\%) got it partially correct.

Problem number 2 takes on Parallel Lines wherein with respect to the identification of the data, 202 $(60.30 \%)$ answered partially correct while $3(0.90 \%)$ answered incorrectly. As for the unknown, 233 $(69.60 \%)$ answered correctly while $0(0.00 \%)$ answered partially correct. Lastly, for the condition, 262 $(78.20 \%)$ left it blank while $2(0.60 \%)$ got the correct answer.

Problem number 3 takes on Perpendicular Lines wherein with respect to the identification of the data, 126 $(37.60 \%)$ left it blank while $4(1.20 \%)$ answered incorrectly. As for the unknown, $221(66.00 \%)$ answered correctly while $3(0.90 \%)$ answered partially correct. Lastly, for the condition, $259(77.30 \%)$ left it blank while $0(0.00 \%)$ got the correct answer.

\subsubsection{Statistics and Probability}

Table 8 reveals the results on the survey along Statistics and Probability as it shows the frequencies and percentages of the accuracies of students' responses for each principal part.

Problem number 1 focuses on Probabilities of Events, particularly on Combination. Results for problem number 1 show that for the identification of the data, $176(52.50 \%)$ respondents answered correctly while only $1(0.30 \%)$ answered incorrectly. As for the unknown, $242(72.20 \%)$ answered correctly while 0 $(0.00 \%)$ answered partially correct. Lastly, for the condition, $180(53.70 \%)$ left it blank while only 2 $(0.60 \%)$ got it partially correct. 
Table 8: Difficulties in Problem Solving Brought About by Identification of Information Along Statistics and Probability

\begin{tabular}{|c|c|c|c|c|c|c|c|c|c|}
\hline \multirow[t]{2}{*}{ Item No. } & \multirow[t]{2}{*}{$\begin{array}{l}\text { Principal } \\
\text { Parts }\end{array}$} & \multicolumn{2}{|c|}{ Correct } & \multicolumn{2}{|c|}{$\begin{array}{l}\text { Partially } \\
\text { Correct }\end{array}$} & \multicolumn{2}{|c|}{ Incorrect } & \multicolumn{2}{|c|}{ Blank } \\
\hline & & $\mathbf{f}$ & $\%$ & f & $\%$ & f & $\%$ & f & $\%$ \\
\hline \multirow{3}{*}{1} & Data & 176 & 52.5 & 66 & 19.7 & 1 & 0.30 & 92 & 27.5 \\
\hline & Unknown & 242 & 72.2 & 0 & 0.00 & 5 & 1.50 & 88 & 26.3 \\
\hline & Condition & 13 & 3.90 & 2 & 0.60 & 140 & 41.8 & 180 & 53.7 \\
\hline \multirow{3}{*}{2} & Data & 100 & 29.9 & 124 & 37.0 & 3 & 0.90 & 108 & 32.2 \\
\hline & Unknown & 228 & 68.1 & 0 & 0.00 & 6 & 1.80 & 101 & 30.1 \\
\hline & Condition & 9 & 2.70 & 23 & 6.90 & 103 & 30.7 & 200 & 59.7 \\
\hline \multirow{3}{*}{3} & Data & 12 & 3.60 & 201 & 60.0 & 2 & 0.60 & 120 & 35.8 \\
\hline & Unknown & 195 & 58.2 & 15 & 4.50 & 7 & 2.10 & 118 & 35.2 \\
\hline & Condition & 19 & 5.70 & 28 & 8.40 & 68 & 20.3 & 220 & 65.7 \\
\hline
\end{tabular}

Problem number 2 focuses on Measures of Variability of Data, particularly getting the Mean. With respect to the identification of the data, $124(37.00 \%)$ answered partially correct while $3(0.90 \%)$ answered incorrectly. As for the unknown, $228(68.10 \%)$ answered correctly while $0(0.00 \%)$ answered partially correct. Lastly, for the condition, $200(59.70 \%)$ left it blank while $9(2.70 \%)$ got the correct answer.

Problem number 3 focuses on Basic Concepts of Probability and Probabilities of Events. With respect to the identification of the data, $201(60.00 \%)$ answered partially correct while only $2(0.60 \%)$ answered incorrectly. As for the unknown, 195 (58.20\%) answered correctly while 7 (2.10\%) answered incorrectly. Lastly, for the condition, $220(65.70 \%)$ left it blank while $19(5.70 \%)$ got the correct answer.

\subsubsection{Overall}

All four strands did have similarities when it came to the results in the identification of information. The identification of the unknown was the least problematic as majority within all strands were able to identify the unknown correctly. The identification of the data follows as majority of the responses in Number Sense were correct while majority were partially correct in the other strands. Lastly, the identification of the condition was most problematic as majority of the responses in Number Sense were incorrect while majority of the respondents left the items blank in the other strands.

\subsection{Difficulties in Problem Solving Brought About by Vocabulary and Identification of Information}

\subsubsection{Vocabulary}

Regardless of the word type, only few respondents indicated difficulties in understanding words. There were a few who may have encircled words because they did not know their roles in the solution process. For example, "How many more" suggests adding to find a total, but "more" may require a subtraction of a smaller number from a larger number to find the answer (Edwards, Maloy, \& Anderson, 2009). Moreover, solving word problems is a comprehension and decoding challenge wherein students need to understand and recall mathematical terms and concepts expressed in words (Edwards, Maloy, \& Anderson, 2009). A teacher conjectured that students take words in problems literally. This statement is built on by another who adds that the functions of words are different when it comes to problem solving as they are not to be taken in the literal sense. For example, when a phrase like 3 less 5 appeared in problems, students took it literally as $3<$ 5 and not $5-3$. Hence, such respondents' analyses and syntheses of ideas in making solution plans were problematic. As Angateeah (2017), Seifi, Haghverdi, and Azizmohamadi (2012), Jupri and Drijvers (2016), Salemeh and Etchells (2016), and Yeo (2009) found that students had difficulties in the translation of problems, these findings could be reasons for such.

Other respondents may have already had a hard time understanding encircled words in the literal sense which made it even harder for them on the inferential and critical senses. As these hindrances to solving 
word problems brought by misunderstanding words, phrases, and sentences were acknowledged by Jupri and Drijvers (2016), this was also found by Edwards, Maloy, and Anderson (2009) who acknowledged that it was hard for students to solve word problems containing terms and phrases that were unfamiliar or unknown to them as they posed challenges to students.

Similar to the findings of Imam, Abas-Mastura, and Jamil (2013) and Özsoy, Kuruyer, and Çakiroglu (2015), these respondents may fail in making plans or may even carry out faulty ones, this time as a result of these difficulties in comprehension.

\subsubsection{Identification of Information}

Regardless of the principal parts and strands, majority were able to identify pieces of information correctly for as long as these were straightforward. This observation strengthens a teacher's observation that students just state the obvious statements of the problem. This was most evident in the identification of the unknown where majority have gotten correct for each item in each strand. Although majority also got the unknown correctly in the problem of Sets under Number Sense, there were partially correct responses observed wherein respondents have failed in giving out all the unknowns. Similarly, most responses in the identification of the data were partially correct as pieces of information were omitted; most of these pieces of data were crucial to the ebstablishment of the conditions. These supplement the findings of Imam, AbasMastura, and Jamil (2013) that students struggled in the identification of main ideas and the noting of details. Despite these, a number of those who gave partially correct responses still had the ideas that these pieces of information were relevant to the establishment of the conditions. This could be linked to teachers' observations that not only do students tend to just state the obvious but "do not really bother to analyze the problems as they tend to look for patterns and similarities to be able to solve problems." These patterns and similarities may be what keep students on track in the establishment of the conditions. Moreover, these solidify that students do not really know what to assume of a problem what pieces of information from the problem are necessary for solving (Phonapichat, Wongwanich, \& Sujiva, 2014).

Although the observations for the identification of the data could also be said for the conditions, there was something bigger to consider. Beyond patterns, the establishment of the condition is an indirect solution of the problem, as a student described. Moreover, one must possess comprehension at critical levels enabling him to analyze, synthesize, and carry out a solution plan. This is only possible if the mastery of concepts is achieved. Since students did not have established grasps to the concepts underneath respective problems, students failed to relate the pieces of information, particularly the data and the unknowns in respective problems, with one another. All these link the findings of Yeo (2009), Raduan (2010), Njagi (2015), and Nguyen and Ngo (2015) that students lacked knowledge on strategies and use of correct formulas and that of Raduan (2010) and Tambychik and Meerah (2010) that students failed to relate, manipulate, and make connections with pieces of information. Consequently, students failed with their processing skills and the explanation of the steps for the establishment of working conditions in the respective problems (Trance, 2013; Vula \& Kurshumlia, 2015).

\subsubsection{Vocabulary and Identification of Information}

The effects of having perceived difficulties in understanding words resulting to difficulties in the identification of information were evident in word problems, particularly in the strand of Geometry and Measurement. Moreover, the following observations strengthened Sepeng and Madzorera's (2014) conjecture that difficulties in decoding meanings in words resulted to failure in producing correct solutions.

Those who indicated difficulties with technical and different-meaning words struggled with the identification of the condition. Taking the first item, respondents who indicated difficulties with the words congruent, third angle, and opposite left the condition blank. As for the latter items, the understanding of the words parallel and perpendicular were still seemed hazy as the essences of both concepts were not met.

There were also exceptions to this implication. Looking at the first item for Number Sense, the word solicit was necessary for obtaining the problem's working condition. Even though majority of the respondents who indicated difficulties with the word only got the data partially, this did not prevent these respondents in 
providing the correct conditions to the problem. This could be linked to the teachers' observation that students rely on patterns to be able to solve problems.

Along with words, this was also seen in numbers as a teacher conjectured that students may not really know how to work with them in problems. Although another teacher added that students probably think that the numbers in the given problems were mere distractors, the previous was more evident as observed in problems on Sets and Triangle Congruence. The respondents knew that the encircled numbers were crucial to the solution but apparently were not adept into working with them. As a respondent encircled a fraction on Operations on Rational Numbers, another teacher commented that the student may be having difficulties with fractions. This was apparent as the student did not get the correct solution plan.

Aside from difficulties in understanding words and numbers, there were those who identified difficulties with phrases, particularly in the strand of Patterns and Algebra. These responses were not tallied but were scrutinized alongside the responses of those who only encircled words. Such responses were understandable as the nature of Patterns and Algebra is deeply concerned with translations of problems into mathematical sentences. It was seen that majority of the respondents were able to identify both the data and the unknown. However, responses ranged from partially correct to blank when it came to the condition. Those who gave partially correct and incorrect responses displayed difficulties in putting connection to the pieces of information and obtained more difficulties in the translation into mathematical sentences and the development of a solution. When asked about this matter, a key informant said that, "the comprehension is there especially for this Age Problem (from the questionnaire). I know that Margie is older and such but the only problem is the translation from a sentence into a mathematical equation because students are used to $x$ $+y$ and $y+x$."

Despite the fact that only a few respondents encircled words and numbers perceived to be difficult, these observations were also evident in responses of those who did not encircle anything. Similar to the other respondents who encircled words, numbers, and phrases, they may have understood them but not the essences that the solutions required. Thus, it was clear that the concepts have not been fully grasped.

This could also be seen in responses to the items under Geometry and Measurement. Taking the first item, respondents did not know where the third angle was situated nor where the opposite to the congruent sides were in their respective illustrations; the illustrations of the triangle were also incorrect. As for the latter items, the understanding of the words parallel and perpendicular were interchanged. Hence, the establishment of the conditions for these items posed problems to the respondents.

\subsection{Challenges in Problem Solving Brought About by Vocabulary and Identification of Information 3.4.1 Concepts}

Underneath the difficulties in problem solving brought by vocabulary and identification of information, it was undeniable that the students' poor grasp of concepts was the main problem. Thus, the very challenge that teachers face is finding ways to teach Mathematical concepts effectively.

Looking into the said problem, teachers found that students fail to remember and relate concepts with one another. They are able to grasp concepts one at a time but end up confused when already faced with multiple concepts in one sitting. Furthermore, only the recent concepts are retained in their minds as they assume that the previous concepts will no longer be needed. For example, Linear Equations were last dealt with on $8^{\text {th }}$ grade, by the time students enter senior high school, they have already forgotten about this. All these support the claim of Sepeng and Madzorera (2014) as they cited Goldberg (2003) saying that students fail to develop their own personal understanding and connection of concepts. Consequently, they end up more confused and more prone to mixing concepts as they fail to recall and differentiate them. This was evidenced by responses to the problem on Linear Inequalities wherein the problem was treated as if it were on Operations on Integers. Two teachers added their experiences on this matter. One teacher recalls his experience in Patterns and Algebra wherein his students used the concept of Derivatives over polynomials when they were only asked to simplify. The other observed that students mix the concepts of Permutation and Combination that it comes to the point that students solve problems on either concept with formulas coming from both. Sepeng 
and Webb (2012) attest that teachers' mechanical way of teaching problems was reason for this problem.

\subsubsection{Reliance on Keywords}

Although it was seen in responses on the questionnaire that students have difficulty in understanding words, teachers still observed that students looked for words which could help them solve the problems. This observation was in accordance to that of dela Cruz and Lapinid (2014). Along these keywords, students looked for question marks which would enable them to identify the unknown. Despite being able to look for these keywords, these would be useless given that the foundation on the concepts underneath these words is weak. A teacher adds that even though students were oriented with various forms of the concepts taught through a variety of words in a variety of word problems, students would still rely on what was primarily taught them instead of putting their higher order thinking skills into work.

\subsubsection{Reliance on Formulas}

Students are also highly reliant on the use of formulas. Although problems do make use of formulas, others require formulation of the working equations. This is the very nature of Patterns and Algebra which students could not grasp as a result of the said reliance on formulas. Moreover, this reliance could be anchored to a culture mainly focused on memorization of steps in solving problems which prevents students in deducing meaning from the process (Schoenfield, 1998; as cited by Sepeng \& Madzorera, 2014).

\subsection{Other Challenges in Word Problem Solving}

As teachers were asked on challenges they have encountered in teaching problem solving to students, there were more challenges specified which were no longer brought about by vocabulary and identification of information skills.

\subsubsection{Essence}

Students do not see the essence of problem solving in their lives. Consequently, students could not visualize these problems even though majority of the students are observed to be visual learners and the said problems are already embroidered with real-life applications. This difficulty could be due to the conventional learning strategies used which do not enable students to improve (Jazuli et al., 2017).

\subsubsection{Familiarity}

It was stated earlier that students were highly reliant on patterns and similarities. Moreover, students would highly rely on problems given and discussed in handouts and classes respectively. This comes to the point where students even demand to their teachers that these problems be given in tests. As teachers give in with changes in figures and phrases, students still manage to complain that such problems were not taught. This shows that students would not want to hone their higher order thinking skills as it delves into making decisions or producing new solutions to multiple real-life situations that are problematic and contained uncertainties, ambiguities, confusions, dilemmas, contradictions, inconsistencies, paradoxes and challenges (King, Rohani \& Goodson, 1997; as cited by Yusoff \& Seman, 2018).

\subsubsection{Assumptions}

Students tend to be intimidated with the lengths of word problems. Supplementing the findings of Phonapichat, Wongwanich, and Sujiva (2014) and Vula and Kurshumlia (2015) that students do not like to read lengthy problems, teachers have observed that students immediately jump into conclusions that problems are difficult when lengthy. Consequently, they give up and resort to complaining.

Contrary to being lengthy, the item on Perpendicular Lines in the questionnaire was left blank by majority of the respondents when it came to the identification of the data and the condition. This also goes to show that students give up without trying when they perceive a problem to be difficult.

Altogether, these solidify teachers' observations which coincided with Hite (2009) and dela Cruz and Lapinid's (2014) that students would rather have it easy by being given the mathematical sentences instead; this is in accordance with. 


\subsubsection{Prejudice}

It is a given that majority of the students loathe Mathematics. This loathe becomes a barrier for teachers to be able to inculcate the needed concepts into the minds of the students. It even gets to the point that students write and draw on their test papers statements like "I hate Math!" and "IDC" (I don't care!) and sketches of their teachers with devil horns. These experiences were far worse from receiving a questionnaire wherein a student wrote "I'm dumb!" Despite these, teachers remain positive and hopeful on students' changes of hearts as soon as Mathematics is established in them. This positivity comes from the understanding that even the teachers themselves loathed Mathematics at least at one point in their lives. Moreover, the attitude of students is paramount in enabling them to learn the discipline as their choice is determined by their attitudes towards Mthematics (Kilpatrick et al., 2001; as cited by Sepeng \& Madzorera, 2014).

\subsubsection{Curriculum Design}

One reason why students tend to perform poorly on Statistics and Probability could be because of the curricuclum design. When it comes to teaching, Statistics and Probability is often compromised. This is because of the fact that the said strand comes at the near end of the school year during the students' junior high school years, particularly grades 7, 8, and 10 as seen in the $\mathrm{K}$ to 12 Curriculum Guide in Mathematics (2012). Consequently, even though teachers perceived the strand to be the easiest, it is not reflected on students' performances as it is no longer paid as much attention to. This effect is reflected in their senior high school years as responses showed poor grasps of the basic concepts given.

\section{Time}

Alongside the curriculum design, topics are only limited to a compact timeframe. Hence, time becomes a factor when it comes to teaching and enabling students in understanding concepts; this includes the teaching of word problems wherein three meetings would not even suffice. Since time is of limited resource, teachers tend to rally the teaching of topics covered.

\subsection{Remedies to the Challenges}

Despite the challenges teachers face in inculcating teaching word problems to the students, actions have been taken and suggestions have also been given to be able to address these challenges.

\subsubsection{Localization}

Localization would definitely enable students to see the essence of problem solving. For example, a teacher uses pesos instead of dollars when it comes to money. Moreover, he changes names in problems to names of students in class for their anxiety to be diverted as attention is focused on their classmates. Consequently, they are most likely to remember the examples and the concepts involved. Rather than becoming sources of distractions as per Edwards, Maloy, and Anderson (2009), names could be an aid for students to retain concepts.

\subsubsection{Real-life Experiences}

Ciaccio (2004), as cited by Sieberer-Nagler et al. (2016), mentioned that it is important to learn to walk in another's shoes. This importance proves to be a big factor that enables students to grasp teachings better. Along this importance, a teacher adds that teaching concepts should be paired with real-life experiences that are analogous to these said concepts. For example, it is given that students find difficulty identifying the abscissa (x-axis) and the ordinate (y-axis) in the Cartesian Plane. As relationships is a topic where many could relate to, talking about exes (past relationships) could be of help for students to remember where the $\mathrm{x}$-axis is. One could say that exes should be buried; this is why the $\mathrm{x}$-axis is on the horizontal plane. Likewise, when it comes to the y-axis, one could relate that to identifying one's "why's". Consequently, one could say that his "why's" is what enables him to stand up; this is why the y-axis takes on the vertical plane.

She adds another example making an analogous statement with asymptotes and "friendzone" (being friends than lovers). Consequently, one could say that the concept of asymptotes is similar to the concept of "friendzone" - so near yet so far. This pertains to the fact that asymptotes approach the $\mathrm{x}$ and $\mathrm{y}$ axes but never do meet and the fact that some people will never be more than friends. 


\subsubsection{Role Playing}

Increasing student engagement in academic activities by changing the way teachers elicit answers to questions represents an option for enhancing wider participation in some components of the curriculum (Parsonson, 2012). One way to do so is through role playing whenever possible. This can help students visualize problems as seen by a teacher who recounted her experience wherein students were better able to visualize and understand the problems more clearly upon doing so.

\subsubsection{Presentation}

Sieberer-Nagler et al. (2016) state that in order for a discussion to be effective, it needs to be carefully prepared. One way to put this into action is through a teacher's experience in making his Powerpoint presentations vivid by assigning colors to pieces of information. He puts the main data in red and the supporting data in yellow, and the unknown in blue. When it comes to the aid of the chalk board, he suggests the use of colored chalks. Nonetheless, these were seen effective in students' learnings as they also made color distinctions in their solutions.

\subsubsection{Instructional Guide}

Effective classroom management involves clear communication of behavioral and academic expectations as well as a classroom environment conducive to learning (Sieberer-Nagler et al., 2016). Moreover, SiebererNagler et al. (2016) assert that clear rules are important for students' academic and social behavior. They add on saying that students' work is much better in environments that are well-defined in terms of dos and don'ts and when they exactly know the rights and wrongs. It is not so good when rules are ambiguous and inconsistent; they need to know what is acceptable and not acceptable behavior (Sieberer-Nagler et al., 2016). Hence, it follows that teachers need to be able to adopt effective ways to be able to teach their students. As teachers find it challenging to develop a good foundation of problem solving in students, one expressed her strategy by adopting the GUFSA method. This method entails the students to see a problem with more clarity by breaking it down into the Given, the Unknown, the Formula, the Solution, and the Answer/s.

\subsubsection{Drills}

Although a teacher was particular with the students' need to have more drills on translation of problems, the need for drills was clearly evident for all concepts and respective word problems in Mathematics. This coincides with the fact that students learn by doing (Sieberer-Nagler et al., 2016). Moreover, teachers should create a dynamic educational environment that affords students the opportunity to practice every concept that they are learning (Sieberer-Nagler et al., 2016). Despite the loathe for the discipline, this is the only way for students to get accustomed to the solving process.

\subsubsection{Building Positive Relationships}

Sutherland et al. (2008) acknowledge that building positive relationships with students is an important antecedent strategy that can serve to reduce disruptive behavior and enhance on-task behavior and student achievement. Moreover, these become the intrinsic motivations prior to being taught in Mathematics. Every once in a while, some teachers have taken action on this matter as they gave students puzzles and played Basketball with them provided that they will have to learn Mathematics and solve afterwards.

\subsubsection{Encouraging Positivity}

Teachers can begin to establish a positive learning environment by showing their passion for the subject matter (Bulger et al., 2002; as cited by Sieberer-Nagler et al., 2016). Hence, it follows that teacher's attitudes towards any discipline is transcended on students. As Mathematics teachers believe that the attitudes of teachers from other disciplines towards Mathematics have strong effects on the students' attitudes to the said discipline, these Mathematics teachers encourage teachers of other disciplines to foster positive attitudes towards Mathematics that students may develop a positive attitude towards the discipline.

Altogether, these actions would enable one to better himself in line with Mathematics given the right motivations that target his learning styles. As one is motivated, he is empowered to keep trying as his skills 
are gradually developed. These would now strengthen his grasp of the discipline while all the wrong practices and attitudes that once hindered him from successfully grasping the concepts are weakened.

\section{Conclusions}

Vocabulary poses difficulties to students in solving word problems as it entails one to decode the concepts underneath words so that conditions could be established. Establishment of relationships among pieces of information to be able to establish conditions is only possible if one has mastered the concepts. The very root of difficulties experienced by students along vocabulary and identification of information is the poor grasp of concepts and high reliance on keywords and formulas which are the very challenges needed to be addressed. Teachers must put emphasis on words which identify to concepts embedded in word problems. This could be done by pointing out words in problems and introducing variations to these words. This would now enable students to be adept in identifying concepts embedded in word problems as they also become able to justify why conditions are established in solving. Students must also enable themselves to be accustomed to such words in problems. Teachers must also put emphasis on relationships among pieces of information in preparation to determining concepts. This could be done by identifying pieces of information that are available and those that are not and bridging them by incorporating the concepts. This would enable students to justify why such concepts are used and why such conditions are established in solving problems. Similarly, students must enable themselves to be accustomed to the relationships among pieces of information in word problems. Teachers must also be keen and vigilant in finding effective ways to be able to inculcate the concepts into the minds of the students as they have the responsibility to push students beyond their limits. Students must learn to set aside their prejudices towards Mathematics and find different ways to grasp the concepts as they are undeniably responsible for the outcome of their learnings. Altogether, teachers and students could strive for these given the remedies discussed and even exceed these out of their creativity. The researcher recommends a tailored instructional guide that could explicitly dissect and partition word problems. Since problems were already given to begin from the understanding of the play of words resulting to faulty conditions and solutions, The REGULATED (Read, Encircle, Given, Unknown, Look back, Analyze, Translate, Execute, and Determine) method was tailored as it also considers vocabulary and the establishment of conditions.

\section{Ethics approval and consent to participate}

This is not applicable for our paper.

\section{Data Availability}

Readers and researchers who are interested in gaining access to our data can reach us through my e-mail address: jc.unson94@gmail.com.

\section{Conflicts of Interest}

I, John Carlo P. Unson, declare no conflicts of interest whatsoever in the publication of our paper.

\section{Funding Statement}

I, John Carlo P. Unson will personally fund the publication of this paper.

\section{Author's Contributions}

JCPU has done everything they could to make this research possible. From the searching of relevant bodies of literature, to the creation of questionnaires, interview questions, and letters of requests for data gathering, to the synthesized of all the bodies of literature and the data in order to be able to create this paper, to the creation of an outcome project which is the REGULATED Method, up until the proofreading and finalization of this paper.

\section{Acknowledgments}

The researcher would like to express his thanks and appreciation to his family members and friends who provided him so much support, concern, and prayers. The researcher would also like to thank their adviser, Dr. Dante L. Caseldo, their panel members, Professors Maria Linda C. Cabillan, J-Lyn C. Espiritu, and Merian E. Abenes, their Graduate Program Coordinator, Dr. Donna Marie A. Oyam, and the Dean of the 
College of Teacher Education, Dr. Ramir S. Austria, for their unwavering support and guidance to the researcher. The researcher would also like to thank all the respondents, key informants, and teachers who have made the data gathering process possible. Above all, the researcher would like to extend his gratitude to the Lord Almighty for making all these possible.

\section{References}

1. Akbaşli, S., Şahin, M., \& Yaykiran, Z. (2016). The effect of reading comprehension on the performance in science and mathematics. Journal of Education and Practice.

2. Angateeah, K.S. (2017). An investigation of students' difficulties in solving non-routine word problems at lower secondary. International Journal of Learning and Teaching, 3(1).

3. Boonen, A.J.H. et al. (2016). Word problem solving in contemporary math education: a plea for reading comprehension skills training. Frontiers in Psychology, 7.

4. Cimmiyotti, C.B. (2013). Impact of reading ability on academic performance at the primary level. Master's Theses and Capstone Projects, 127.

5. Cruz, M.V. \& Bullecer, M.F. (2016). Dual language fluency and math word problem performance of selected students. The Bedan Journal of Psychology 2016, 1.

6. Dela Cruz, J.K.B. \& Lapinid, M.R.C. (2014). Students' difficulties in translating worded problems into mathematical symbols. Presented at the DLSU Research Congress 2014.

7. DepEd K to 12 Curriculum Guide in Mathematics, s. 2012.

8. DepEd National Training of Trainers on K to 10: Mathematics 8, s. 2018.

9. Eby, M. (2016). Integrating reading into mathematics instruction. University Honors Program Theses, 182.

10. Edwards, S.A., Maloy, R.W., \& Anderson, G. (2009). Reading coaching for math word problems. Literacy Coaching Clearinghouse.

11. Fatmanissa, N. \& Kusnandi (2017). The linguistic challenges of mathematics word problems: a research and literature review. Malaysian Journal of Learning and Instruction (MJLI), Special Issue on Graduate Students Research on Education, 73-92.

12. Hite, S. (2009). Improving problem solving by improving reading skills. Summative Projects for MA Degree, 9.

13. Imam, O.A., Abas-Mastura, M., \& Jamil, H. (2013). Correlation between reading comprehension skills and students' performance in mathematics. International Journal of Evaluation and Research in Education, 2(1), 1-8.

14. Jazuli, A. et al. (2017). Improving conceptual understanding and problem-solving in mathematics through a contextual learning strategy. Global Journal of Engineering Education, 19(1), 49-53.

15. Jupri, A. \& Drijvers, P. (2016). Student difficulties in mathematizing word problems in algebra. Eurasia Journal of Mathematics, Science \& Technology Education, 12(9), 2481-2502.

16. Ketterlin-Geller, L.R., Chard, D.J., \& Fien, H. (2008). Making connections in mathematics conceptual mathematics intervention for low-performing students. Remedial and Special Education, 29(1), 33-45.

17. Langenes, J. (2011). Methods to improve student ability in solving math word problems. Hamline University, St. Paul, MN.

18. Laurito, P.P., Duallo, N.M., \& Pecajas, E.S. (2016). Correlation of comprehension skills and mathematical ability in geometry of the students of naval school of fisheries. International Journal of Engineering Sciences \& Research Technology.

19. Nguyen, P.L. \& Ngo, T.P. (2015). Opinions on mathematics word problems in primary schools: a survey of teachers and students in the city "Bac Lieu" - Vietnam. European Academic Research, 2(11).

20. Njagi, M.W. (2015). Language issues on mathematics achievement. International Journal of Education and Research, 3(6).

21. Ogena, E.B., Laña, R.D., \& Sasota, R.S. (2010). Performance of Philippine High Schools with Special Science Curriculum in the 2008 Trends in International Mathematics and Science Study (TIMSS-Advanced). 
22. Özsoy, G., Kuruyer, H.G, \& Çakiroglu, A. (2015). Evaluation of students' mathematical problem solving skills in relation to their levels. International Electronic Journal of Elementary Education, 8(1), 113-132.

23. Parsonson, B.S. (2012). Evidenced-based classroom behaviour management. Kairaranga 2012, 13(1).

24. Pearce, D.L. et al. (2013). What teachers say about student difficulties solving mathematical word problems in grades 2-5. International Electronic Journal of Mathematics Education, 8(1).

25. Phonapichat, P., Wongwanich, S. \& Sujiva, S. (2014). An analysis of elementary school students' difficulties in mathematical problem solving. Procedia - Social and Behavioral Sciences, 116, 31693174.

26. Polya, G. (1973). How to solve it: a new aspect of mathematical method. Princeton, New Jersey: Princeton University Press.

27. Raduan, I.H. (2010). Error analysis and the corresponding cognitive activities committed by year five primary students in solving mathematical word problems. Procedia Social and Behavioral Sciences, 2, 3836-3838.

28. Salemeh, Z. \& Etchells, M.J. (2016). A case study: sources of difficulties in solving word problems in an international private school. Electronic International Journal of Education, Arts, and Science 2016, 2, 149-163.

29. Seifi, M., Haghverdi, M., \& Azizmohamadi, F. (2012). Recognition of students' difficulties in solving mathematical word problems from the viewpoint of teachers. Journal of Basic and Applied Research, 2(3), 2923-2928.

30. Sepeng, P. \& Madzorera, A. (2014). Sources of difficulty in comprehending and solving mathematical word problems. Int J Edu Sci, 6(2), 217-225.

31. Sepeng, P. \& Webb, P. (2012). Exploring mathematical discussion in word problem-solving. Pythagoras, 33(1), 1-8.

32. Sieberer-Nagler, K. et al. (2016). Effective classroom-management \& positive thinking. English Language Teaching, 9(1), 163-172.

33. Suan, J.S. (2014). Factors affecting underachievement in mathematics. Proceeding of the Global Summit on Education GSE 2014.

34. Sutherland, K. S. et al. (2008). Examining the influence of teacher behaviour and classroom context on the behavioural and academic outcomes for students with emotional or behavioural disorders. Journal of Special Education, 41(4), 223-233.

35. Tambychik, T. \& Meerah, T.S.M. (2010). Students' difficulties in mathematics problem-solving: what do they say? Procedia Social Science and Behavioral Sciences, 8, 142-151.

36. Trance, N.J.C. (2013). Process inquiry: analysis of oral problem-solving skills in mathematics of engineering students. US-China Educational Review A, 3(2), 73-82.

37. Vilenius-Tuohimaa, P.M., Aunola, K., \& Nurmi, J.E. (2008). The association between word problems and reading comprehension. Educational Psychology, 28(4), 409-426.

38. Vula, E. \& Kurshumlia, R. (2015). Mathematics word problem solving through collaborative action research. Journal of Teacher Action Research.

39. Yusoff, W.M.W. \& Seman, S.C. (2018). Teachers' knowledge of higher order thinking and questioning skills: a case study at a primary school in Terengganu, Malaysia. International Journal of Academic Research in Progressive Education and Development, 7(2), 45-63. 